\title{
Clinical teaching of student nurses by unit managers of selected hospitals in Limpopo Province
}

\author{
LA Murathi, MCur Student, Thohoyandou Nursing Campus, University of Venda for \\ Science/Technology \\ M Davhana-Maselesele, DPhil, Thohoyandou Nursing Campus, University of Venda \\ for Science/Technology \\ VO Netshandama, D Cur, Thohoyandou Nursing Campus, University of Venda for \\ Science/Technology
}

\begin{abstract}
The comprehensive nature of nurse training needs the involvement of almost all health team personnel, including unit managers to gain practical experience and learn to correlate theory and practice. The overall aim of the study was to explore and describe the experiences of unit managers regarding teaching of student nurses in the clinical area and to develop recommendations that will enhance clinical teaching, for the production of competent future nurse practitioners who will render quality care to patients. A qualitative design, which is explorative, descriptive and contextual in nature, was employed, utilizing a phenomenological approach to capture the experiences of unit managers regarding teaching of student nurses at selected hospitals, where students are allocated for their clinical exposure. Ethical measures as well as measures to ensure trustworthiness were adhered to. In-depth phenomenological interviews were conducted with unit managers who shared their experiences regarding clinical teaching of student nurses. Data analysis was done according to Tesch's (1990) open coding method.

One major theme emerged, namely that unit managers experienced problems when doing clinical teaching of student nurses. Based on the findings the following recommendations were made: Colleges should open a two-way communication with unit managers, involvement of unit managers in the activities that take place at the college like courses, seminars and workshops on clinical teaching, learning contracts should be developed for the students and issues of clinical learning should be addressed and unit managers should be included in both summative and formative evaluations.
\end{abstract}

\section{Background and orientation of the problem}

Since time immemorial, unit managers (matrons) have borne the responsibility for the nurses' entire education programme, including theoretical and practical teaching, and experience. Nurse training was associated with an apprenticeship system of education, which involved instruction in defined vocational skills, practical problem solving and inculcation of good working habits in nurses, in order to provide a safe public service. The education, however, was informal (Pendelton \& Myles, 1992:3). This type of training was offered to a group of nurses employed by a particular hospital, with the matrons teaching theory in the afternoons. Supervision, guidance and teaching of clinical skills were done by ward sisters (Potgieter, 1992:140, 147). In 1983 the Ministers of Education and National Health announced that nursing colleges would be autonomous and that courses should be offered in association with universities (Mellish \& Paton, 1999:45).

Significant changes occurred in nurse training and a more holistic approach to rendering nursing care to clients emerged. Yoder, Cohen and Gorenberg (1998:121) recorded that innovative ways of teaching student nurses were developed so that care could be rendered in a comprehensive and holistic way.

The hospitals that were offering clinical exposure to student nurses on behalf of colleges were also affected by this reorganisation of nurse education and training. Certain changes and adjustments were made. These changes affected the clinical teaching of student nurses by unit managers in the clinical area. Among the other responsibilities of unit managers such as patient care, administration, education and research, the challenge was to strike a balance. It appears, however, as if the teaching of student nurses by 


\section{Problem statement and research objectives}

The teaching of student nurses in the clinical area has become a problem. The hospitals investigated during this study, selected a few unit managers to be preceptors for the campus/college of nursing, and clinical departments were created where these preceptors were stationed, away from the units, instead of placing them in the units as recommended by Reilly and Oermann (1992: 196). An effort was made to address the changes which had taken place in nursing education. Unit managers, who were not selected as preceptors, overlooked the teaching of student nurses in the clinical area. Several problems developed regarding clinical teaching, some of which are as follows:

- Unit managers experience problems in balancing their functions, and in the end, clinical teaching is not done.

- There is no communication between nurse educators and unit managers, except through the preceptors.

- $\quad$ There appears to be role confusion. It is not clear who should teach students, the preceptor or the unit manger.

This study attempts to raise unit managers' awareness regarding their important role of teaching student nurses.

Two objectives set for the study were to:

- $\quad$ explore and describe the experiences of unit managers regarding the teaching of student nurses in the clinical area; and

- develop strategies that enhance the clinical teaching of student nurses.

\section{Research design and method}

A qualitative, exploratory, descriptive and contextual design was utilised to conduct this research (Mouton \& Marais 1993:45; Mouton, 1996:103-109). Experiences of specific unit managers regarding the teaching of student nurses in the selected specific clinical area were explored and described, in order to develop strategies that would enhance clinical teaching.

\section{The population and} sampling

According to Polit \& Hungler (1993:235) "population" is the entire group about which information is desired. The population targeted for this study was composed of unit managers, both female and male, who had spent five to ten years in actual clinical service in the selected hospitals. Unit managers from different disciplines were included, namely General Nursing Science, Psychiatric Nursing Sci-
The researcher decided upon purposive sampling for the study, bearing in mind that the method involves deliberate selection of particular elements within a group for a specific purpose (Burns \& Grove, 1993:246). Selection was based upon the researcher's knowledge of the population (Brink, 1996:140). In this study, unit managers were selected because of their expertise, and being in charge of all activities that take place in these units, including the clinical teaching of student nurses.

\section{Measures to ensure trustworthiness}

Lincoln and Guba's (1985:218-331) four strategies of trustworthiness were followed to ensure the establishment of trustworthiness. The researcher had prolonged engagement with each unit manager during data collection, and the researcher's experience as a clinical tutor assisted in detecting distortions. Utilising multiple sources of data ensured triangulation. A dense description of data by the researcher provides other researchers with the required information, should they wish to prove transferability. Findings are solely those of the participants and conditions of the study, without being influenced by the researcher. Bracketing was applied, where the researcher does not impose her preconceived ideas upon participants during the course of the interviews.

\section{Ethical consideration}

Permission to conduct the study was requested from the:

- Head of the Department of Health and Welfare of Limpopo Province;

- Regional Office Vhembe District; and

- Superintendents and hospital nursing managers of the three selected hospitals respectively.

In this study, the rights of participants were protected by maintaining the ethical standards as stipulated in the Ethical Standards for Nurse Researchers set out by the Democratic Nursing Organisation of South Africa (1998:2-3), covering issues of confidentiality, anonymity and informed voluntary consent. Participants were referred to as participant 1, 2, 3, etc., and hospitals were named Hospital A, B and $\mathrm{C}$.

\section{Data collection method}

In-depth phenomenological interviews were conducted with unit managers sharing their experiences regarding clinical teaching of student nurses. The researchers' intentions were to encourage unit managers to narrate their experiences regarding clinical teaching of student nurses as comprehensively as possible (Glesne \& Peshkin, 1992:85). Unit managers were therefore interviewed separately so that they could describe as precisely as possible what they experienced and how they felt, and how they acted. It was prima- 


\begin{tabular}{|c|c|c|}
\hline THEME & CATEGORIES & SUB-CATEGORIES \\
\hline \multirow[t]{4}{*}{$\begin{array}{l}\text { Unit managers expressed } \\
\text { the problems they en- } \\
\text { countered whilst render- } \\
\text { ing clinical teaching } \\
\text { amongst student nurses. }\end{array}$} & $\begin{array}{l}\text { Unit managers felt that there is } \\
\text { poor communication with the } \\
\text { teaching staff; }\end{array}$ & $\begin{array}{l}\text { - Poor relationships with the teaching staff. } \\
\text { - } \quad \text { Poor orientation of students and unit managers. } \\
\text { - } \quad \text { Unequal placement of preceptors. }\end{array}$ \\
\hline & $\begin{array}{l}\text { Unit managers expressed that stu- } \\
\text { dents displayed different atti- } \\
\text { tudes as they were taught; }\end{array}$ & $\begin{array}{l}\text { - Refusal of students to perform delegated respon- } \\
\text { sibilities. } \\
\text { Lack of accountability of students towards unit } \\
\text { managers. } \\
\text { - }\end{array}$ \\
\hline & $\begin{array}{l}\text { Unit managers experienced short- } \\
\text { age of staff; }\end{array}$ & $\begin{array}{l}\text { - Unit managers expressed that they are over- } \\
\text { worked. }\end{array}$ \\
\hline & $\begin{array}{l}\text { Unit managers expressed prob- } \\
\text { lems related to teaching and evalu- } \\
\text { ating students. }\end{array}$ & $\begin{array}{l}\text { - Lack of commitment to clinical teaching. } \\
\text { Exclusion of unit managers from evaluation of } \\
\text { students. }\end{array}$ \\
\hline
\end{tabular}

rily the task of the researcher to evaluate the questions directed at the interviewee about the experiences in order to understand why they acted the way they did. The question was, What are your experiences regarding the teaching of student nurses in the clinical area? Subsequent questions were stated to encourage the participants to elaborate and clarify their experiences regarding clinical teaching of student nurses. A private place was sought to encourage free discussion without any threats. The interview was conducted in English.

An audiotape was used to capture the data from the interviews and to enable the interviewer to keep her full attention focused on the participants, in order to observe and be able to interpret vocalisation, facial expressions and bodily gestures, and to jot down field notes during the discussions. Data saturation occurred after six unit managers were interviewed, which was evidenced by repetition of themes.

\section{Data analysis}

Tesch's open coding method which comprises of eight steps of data analysis (in Creswell, 1994:155) were employed as a guide in developing themes, categories and subcategories, and direct quotes were extracted from the transcriptions. Field notes were also analysed to develop their relationship with the interviews and create categories (Wilson, 1989: 380). An independent coder coded the information gathered. The researcher and the independent coder met, and had a consensus discussion about the theme, categories and sub-categories that had been identified (Creswell, 1994: 155).

\section{Findings and discussion}

One major theme emerged from the interviews and four cat- egories were identified, table 1 gives a summary of the findings. The theme, categories and sub-categories were discussed in detail and were supported by direct quotes from the inputs of unit managers. Literature control was done to verify the findings, whether the identified theme was also obtained by other researchers. The following is a discussion on the findings as well as the conclusions drawn from the findings.

\section{Main theme: Unit managers expressed the problems they encountered whilst rendering clinical teaching amongst student nurses.}

During interviews it was found out that managers are experiencing more problems than positive experiences this was supported by the following categories:

- Unit managers felt that there is poor communication with the teaching staff;

- Unit managers expressed that students displayed different attitudes as they were taught;

- Unit managers experienced shortage of staff;

- Unit managers expressed problems related to teaching and evaluating students.

\section{Unit managers felt that there is poor communication with the teaching staff}

Participants stated during interviews that there was poor communication with the teaching staff. The campus/clini- 
cal department does not communicate with them concerning the needs of students during their stay in the units, except to provide them with the learning objectives, after a struggle. Unit managers said: "We, unit managers do not communicate with the campus except through the clinical department, sometimes, we get information from students which you are not sure how true it is."

Poor communication with the teaching staff of the campus was also confirmed by another participant who said: "I think we as unit managers should have communication with the campus, so that every time the students are coming from campus we should know what was dealt with so that whatever is lacking we can emphasize it at the hospital."

Chabeli (1999: 24) mentioned that communication between the college and the units may assist to create a conducive learning environment for nursing students.

Communication should be established between the campus and unit managers as it creates a link. The clinical units are facilities where students are allocated for their clinical exposure. Learning objectives, procedure manuals and evaluation tools should be distributed to unit managers so that the teaching of student nurses may run smoothly, and to curb the following problems that were identified as subcategories:

- $\quad$ poor relationships with the teaching staff;

- $\quad$ poor orientation of students and unit managers;

- lack of consultation with unit managers; and

- unequal placement of preceptors.

\section{- Poor relationships with the teaching staff}

Poor relationships between tutors and unit managers are the result of poor communication. Unit managers stated during interviews that there is lack of frequent contact with the teaching staff. They are not given moral support and are not assisted in solving any of the students' problems in the clinical area. According to one unit manager, "Tutors sometimes do visit the wards but rarely, we only see them during evaluations." Other unit managers expressed poor relationships with teaching staff as follows: "We are demoralised by lack of involvement; the teaching staff do not tell us anything about what has been done in the college and what we are expected to do with the students in the wards."

Good interpersonal relationships between tutors and unit managers are necessary to enhance team performance and openness when dealing with students (Valentine, in Cox, 2001:8).

The presence of tutors assists in enhancing the shared responsibility of teaching, because students realise the importance of both clinical and theoretical learning.

\section{- Poor orientation of students and unit managers}

Unit managers indicated that due to poor communication, orientation of students is not done satisfactorily either by the campus or the clinical department. Unit managers further stated that they also need orientation because of many changes in nurse training. They are not sure whether what they teach is still relevant. According to unit managers, "Students are just dumped in the wards by clinicians/preceptors without being shown the people they are going to work with, who are ward sisters." One participant said: "We are not sent for courses/seminars for teaching so that we will be up to standard in what is expected of us. We are outdated especially for those without a specialty in nursing education and it is difficult to teach students in the wards."

According to Orton (in Matthews and Whelan 1995: 215) effective learning of students takes place in the wards with a high standard of orientation.

Naudé et al (1999:236) state that to provide for the mental expectations and desires of personnel in an institution, orientation, in-service education in the form of workshops, symposia as well as continuous education should be promoted to empower personnel and facilitate career development.

Nursing education has undergone many changes and therefore calls for all stakeholders involved in teaching nurses to be up to date with recent changes and developments in the profession. Therefore unit managers who are expected to provide clinical teaching to nursing students are not an exception to this.

\section{Lack of consultation with unit managers}

Unit managers indicated during interviews that there is lack of consultation; preceptors remove students from the units without communicating with unit managers about anything concerning students' movements, and making no attempt to keep unit managers informed of the students' whereabouts. Participants said: "They remove students from the units without consulting us as unit managers; we don't know their normal hours of attending procedures; this almost collide with lectures given by unit managers, and miss on demonstrations that are relevant to that particular ward."

Lack of consultation of unit managers affects the planning of clinical teaching of students as the programme is not discussed before the students are called to the lecture room. Therefore specific things that they need to learn from the unit are usually missed out.

\section{- Unequal placement of preceptors}

During interviews it transpired that in the clinical area, there are certain units with preceptors who are part of the unit team, e.g. maternity and psychiatric units, but there are those units without preceptors stationed in their teams. In the general units, e.g. medical, surgical, paediatric, outpatient and the operating theatre, there are no preceptors. These units experience more problems with students than the ones with preceptors, as a result of poor communication. Unit managers without preceptors stated that they 
were not happy about the allocation of some of the preceptors to the clinical department, rather than to the units because other units had preceptors who were always there. One unit manager said: "Preceptors must be allocated in the wards, where they will always be there with students. We do not understand the fact that there are certain wards with preceptors, and others without preceptors, and this is only happening in the general wards, not in maternity and psychiatric wards."

Oermann (2001: 26) argues that a preceptor meets with the student and a new graduate in the unit throughout the day to answer questions, helps organize care and assists in making clinical judgments.

It is important for each unit to have a preceptor as this person acts as a link between the college and the unit and hence facilitate the process of communication.

\section{Unit Managers expressed that students displayed different attitudes}

Unit managers stated during interviews that student nurses display different attitudes while they are with them in the units. Some students display positive attitudes while others are negative towards unit managers. Most of the negative attitudes are observed where preceptors are not stationed in the units. The negative behaviour displayed most often includes the following:

- refusal to perform delegated responsibilities;

- lack of accountability of students towards unit managers; and

- lack of respect for unit managers on the part of students.

\section{- Refusal to perform delegated responsibilities}

Unit managers complained about the negative behaviour of nursing students, which is observed mostly in units without preceptors. Unit managers said: "The integrated students do not like carrying out allocated work; they think that some of the work is not theirs, it is for other categories. Things like dusting, feeding patients, giving of bedpans ... they even refuse to transfer patients to other institutions and when you ask why are they not going, they give vague excuses; students do not take instructions from us because they know that we do not have a say in their progress in clinical learning."

Chabeli (1999: 24) states that student nurses are no longer sensitive to clinical practice and they do not regard clinical teaching as an important component in their training, regardless of the fact that nursing is a hands-on profession. Unit managers associate refusal of students to perform delegated responsibilities with their lack of involvement in their final clinical progress report.

Other unit managers however had a different opinion regarding refusal of student nurses delegation as they indi- cated that not all students refuse delegation.

It was found that students working in units where there are preceptors, display positive behaviour. Participants from units with preceptors described the behaviour of students as follows: "Students are mature enough; it shows that they are towards completion They tend to allocate themselves when they arrive here, before you show them the delegated duties. They initiate learning by preparing procedures on their own and then they will call you to come and facilitate the procedure. They will also ask you to elaborate where they are not clear, and we find them to be very competitive."

From the findings one could conclude that units with preceptors have fewer problems than those without as the students are aware that their behavior might affect their clinical progress report. This shows an important role played by the preceptor who is working with student nurses role modeling the correct behaviour expected from them.

\section{Lack of accountability of students towards unit managers}

Participants stated during interviews that students disappear from the units without trace during hours of attendance. Unit managers said: "They 'dodge' to the nurses' home to have breakfast during working hours, which should be done before coming to work. They 'dodge' while we are busy with morning routine; you will just see that they are missing, not one, they just go, as a group. They do not report their movements."

Bradley and Edinberg (1986: 153) state that the act of taking charge, gaining control, or making your viewpoint known in a situation that is out of control may be perceived differently.

Although unit managers understand that it is their responsibility to make sure that students observe their clinical hours, they still feel that the college should put a disciplinary mechanism for the students who are at the clinical units.

\section{students}

Unit managers stated that students undermine their authority while in the units. They are uncontrollable and unit managers feel embarrassed about the way students sometimes answer them back in the units. Unit managers said: "The integrated students undermine our authority as sisters; sometimes if it comes to a push, you can come to the point of chasing them out of the ward ... (angry, clenching fists); they will just sit down without doing anything especially when you are with them on night duty. When you talk to them, they just answer the way they like."

Naude et al (1999: 84) stress that the neophytes in nursing should respect the persons who are knowledgeable and in control like unit managers. Respect is a two way process. It is therefore also expected that unit managers also show 
respect towards the students, acknowledging the existing knowledge and experience that students brought to nursing which also supplement the knowledge and experience of unit managers.

In addition McCloskey and Grace (1990: 510) state that the inability to specify behaviour expected of students towards professional nurses is the source of multiple problems in nursing units. It has also contributed to the rigid hierarchy of control in the history of nursing which was militant and is still militant in health care setting which subordinates refute excessive control.

\section{Unit managers experienced shortage of staff}

During interviews unit managers cited the problem of shortage of staff, which sometimes interferes with the teaching of student nurses in the clinical area. This was explained by the following subcategory:

- Unit managers expressed that they are overworked.

\section{Unit managers expressed that they are overworked}

All participants complained about the excessive workload that they are supposed to carry on their own and add clinical teaching to their busy schedule.

They said: "Shortage of staff sometimes affect the teaching programme of student, but in a way that can be compensated back if there is co-operation; it must be known that as unit managers, we are not only responsible for students teaching ..." Time is so limited for us therefore if students are not motivated to learn and also not avail themselves it is going to be very difficult for them to learn."

The problem of shortage of staff is confirmed by several studies conducted by McCaugherty (1991:1061), Lathlean (1992: 236-237) and Bezuidenhout et al (1999: 46). They found that there is shortage of qualified of professional nurses to can provide effective clinical teaching of students because of the excessive workload that they are expected to carry, that of unit administration, provision of patient care and research.

Unit managers have multiple roles to play, therefore they need to balance their time so that all of their roles are attended to satisfactorily. Students need to cooperate to ease the burden on the unit manager.

\section{Unit managers expressed problems of teaching and evaluating students}

Unit managers indicated during interviews that there are problems concerning clinical teaching that some of them had decided to abandon student teaching, but others still continued to teach students. The problems were outlined as follows:

- lack of commitment to clinical teaching; and

- $\quad$ exclusion from evaluation of students.
- Lack of commitment to clinical teaching

Some unit managers indicated during interviews, that they were not going to work for others, and that it was not their work. They said: "We are not going to work for tutors while they are seated at the college. We are not paid for that job. It must be known that we have shortage of manpower and even if we can teach we are not allowed to sign the procedure file of students." But there are those unit managers who still feel that teaching of students is their duty. They said: "We teach them because we want to form part of the students' learning progress."

Nurse managers should also provide a safe, friendly and professional environment for student nurses to learn and become skilled and competent professional nurses (Naude, Meyer \& Van Niekerk, 1999:84-85).

Unit managers should bear in mind the fact that they are the gate keepers of the profession and that they have expert knowledge in clinical teaching.

\section{Exclusion from evaluation of students}

Unit managers stated that they felt discouraged from continuing with teaching because they were not sure whether their teaching is appreciated by the teaching staff or whether it benefits students. They said: "We, unit managers, are not given a chance to evaluate the students or sign their workbooks after we have taught them, we end up not knowing how much the students benefited from our teaching."

According to Klopper (1994, monograph 2:20) continuous assessment, evaluation and providing feedback on the learner's clinical work is essential and a necessity for effective and efficient learning and guidance. This type of evaluation should be provided by unit managers when they are working with students in the units during their clinical exposure.

Unit managers should also have a way of assessing what they have taught the students as this will guide the unit managers on whether they should improve on their teaching skills or not. Therefore they need to be included in both summative and formative assessments.

\section{Limitations}

The study was confined to the general wards, maternity and psychiatric units of one campus. The findings cannot be generalised to the other two campuses and their clinical facilities. It needs a follow-up study of this nature that will be inclusive of all the clinical facilities of the Limpopo College of Nursing in order to identify similarities and differences among problems experienced by unit managers in the clinical area while doing clinical teaching with students.

\section{Recommendations based on the findings}

After considering aspects that appear to be problems expe- 
rienced by unit managers in the clinical area, the following recommendations are made:

- The campus should open a means of two-way communication with the clinical units to curb the misinformation delivered to unit managers by students; holding regular meetings with unit managers to discuss some of the problems that occur in the units will promote harmony between the campus and the clinical area.

- Two-way communication acts as a feedback mechanism, to find out whether resolutions taken concerning student training at early meetings have been successful or not.

- Good communication promotes team spirit and maintains good interpersonal relationships among the teaching staff and unit managers and therefore enhances effective clinical learning (Matthews \& Whelan, 1995:5).

- Unit managers should be involved in the activities that take place at the college, like courses, seminars and workshops on clinical teaching, because they are deeply involved with students in the clinical area.

- Unit managers should be invited to attend special occasions that take place at the campus/college that involve students like graduation ceremonies and students' day ceremonies. This will make them feel that they are part of students' learning and therefore bolster their morale.

- Tutors should visit the units frequently for accompaniment; they should work with students while supervising them. They will also assist unit managers with some of the students' problems, especially those associated with students' learning.

- The tutors' accompaniment programme should be made available to unit managers, so that they will be aware that on such a day tutor so and so will visit us. If the arrangement is not honoured the concerned tutor should notify the concerned unit to promote harmony.

- The unit teaching programme should also be known to the teaching staff to avoid clashes between programmes; this will improve consultation for both parties.

- $\quad$ Preceptors should be allocated to the units to avoid removing students for procedures at certain times. As it has been found out that units with preceptors experience fewer problems with students than those units without preceptors therefore their presence will curb the problem.

- The clinical teaching of students should be done in that particular unit where the students are allocated, e.g. if the student is in the surgical ward for that period, the procedures that she/he should be taught should be surgical procedures.

- $\quad$ The college should make sure that students sign a learning contract that elaborates the type of behaviour expected when the student is either on block or in the clinical area during her/his training period. The college should implement some form of disciplinary action against students who misbehave in the clinical area.

- Unit managers should be allowed to sign students' workbooks after they have taught them in the units.

- Unit managers must be included in both formative and summative evaluation of students, as they are the people who see everything the students do in the units on a daily basis.

\section{Recommendations for research}

Much more research needs to be conducted which is in a broader scope as the findings of this study were contextualized in one campus. The study could be expanded to the whole Province.

To successfully address the problem effectively there is a need to conduct research on the experiences of student nurses regarding clinical teaching.

\section{Conclusion}

Many problems that hinder effective clinical teaching have been highlighted by unit managers. It needs all stakeholders involved in clinical learning of student nurses, including students themselves, to be involved in eliminating the problems experienced in the units by unit managers during clinical teaching, by implementing the recommended strategies. Since clinical teaching problems are experienced in almost all clinical facilities in academic hospitals, the strategies recommended could serve as a frame of reference to enhance clinical teaching.

Regardless of the many problems identified in the clinical area, unit managers still have the responsibility to teach, supervise, guide and mentor student nurses in the clinical area to produce qualified, competent nurse practitioners and they must do it because it is one of their broad functions.

\section{References}

BEZUIDENHOUT, MC. \& KOCH,S \& NETSHANDAMA, VO 1999. The role of ward managers in creating a conducive clinical learning environment for nursing students. Curationis 23(9) 46-51.

BRADLFY, JC \& EDINBERG, MA. 1986. Communication in the nursing context. Second edition, Appleton: Century Crafts.

BRINK, HIL. 1996. Fundamentals of research methodology for health care professionals. Cape Town: Juta.

BURNS, N \& GROVE, SK. 1993. The practice of nursing research, conduct, critique and utilization. Philadelphia: W.B. Saunders.

CHABELI, M. 1999. Student nurses' learning needs and expectations in the clinical learning units. Curationis. 23(12):24-28.

COX, KB. 2001. The effects of unit morale and interpersonal relations on conflict in the nursing unit. Journal of Advanced Nursing. 35(7): 1 .

CRESWELL, JW. 1994. Research design, qualitative and 
quantitative approach. New Delphi: Sage.

DEMOCRATICNURSING ORGANIZATIONOFSOUTH

AFRICA, 1998: Ethical standards for nurse researcher. Pretoria: DENOSA.

GLESNE, CG \& PESHKIN, A. 1992: Becoming a qualitative researcher. An introduction. New York: Longman.

KLOPPER, HC. 1994: The learning accompanist in nursing science. Johannesburg: Rand Afrikaans University.

LATHLEAN, J. 1992: The contribution of lecturer practitioner to theory and practice in nursing. Journal of clinical nursing. 1(5):236-242.

LINCOLN, VS \& GUBA, EG. 1985: Naturalistic Inquiry. London: Sage.

MATTHEWS, A \& WHELAN, J. 1995: In charge of the ward. London: Blackwell Science.

MCCAUGHERTY, D. 1991: The theory-practice in nurse education; its causes and possible solutions. Journal of Advanced Nursing. 16(March): 1055-1061.

MCCLOSKEY, SC. \& GRACE. HK. 1990: Current issues in nursing. Third ed, CV Mosby.

MELLISH, JM \& PATON, F. 1999: Ethos of Nursing. Sandton: Heinemann.

MOUTON, J. 1996: Understanding social research. Pretoria: Van Schaik.

MOUTON, J \& MARAIS, HC. 1993: Basic concept in methodology for human Sciences. Pretoria: Human Sciences Research Council.

NAUDE, N, MEYER, S \& VAN NIEKERK, S. 1999: The Nursing unit manager. A Comprehensive Guide. Sandton: Heinemann.

OERMANN, MH \& GARVIN, MF. 2001: Mentoring in nursing, NURSES. Nursing Management. 32(1): 26-27.

PENDLETON,S \& MYLES, A. 1991: Curriculum planning in Nursing Education. Practical Applicaton. London: Edward Arnold.

POTGIETER, E. 1992: The Nursing Profession. Johannesburg: Juta.

REILLY, CE \& OERMANN, MH. 1992. Clinical teaching in nursing education. $2^{\text {nd }}$ edition. New York: NLN.

YODER, MK, COHEN,J \& GORENBERG, B. 1998: Transforming the curriculum while serving the community: strategies for developing community based sites. Journal of Nursing Education. 37(3):118-121.
WILSON, HS. 1989: Research in nursing. Second edition. California: Addision-Wesley. 